\title{
Effect of CO2 Laser and Fluoride Varnish Application on Microhardness of Enamel Surface Around Orthodontic Brackets
}

\author{
Majid Mahmoudzadeh"1, Loghman Rezaei-Soufi'², Nasrin Farhadian', Seyed Farzad Jamalian ${ }^{3}$, Mahdi \\ Akbarzadeh $^{4}$, Mohammadali Momeni ${ }^{5 *}$, Masome Basamtabar ${ }^{6}$ \\ ${ }^{1}$ Orthodontics Department, Dental Research Center, Hamadan University of Medical Sciences, Hamadan, Iran \\ ${ }^{2}$ Department of Restorative Dentistry, Dental Research Center, Hamadan University of Medical Sciences, Hamadan, Iran \\ ${ }^{3}$ Private Practice, Hamadan, Iran \\ ${ }^{4}$ Department of Biostatistics, Hamadan University of Medical Sciences, Hamadan, Iran \\ ${ }^{5}$ Orthodontics Department, Dental Faculty, Shahrekord University of Medical Sciences, Chaleshtar, Shahrekord, Iran \\ ${ }^{6}$ Orthodontic Department, Dental Faculty, Kermanshah University of Medical Sciences, Kermanshah, Iran
}

\section{*Correspondence to Mohammadali Momeni, Orthodontics Department, Dental faculty, Hamadan University of Medical Sciences, Shahid Fahmideh Blvd. Hamadan, Iran Tel: +989194886113 Fax: +98 8138381085 Email: ortho.momeni@gmail.com}

Published online 26 December 2017

\begin{abstract}
Introduction: Orthodontic treatment has many advantages such as esthetic improvement and self-esteem enhancement; yet it has some disadvantages such as increasing the risk of formation of white spot lesions, because it makes oral hygiene more difficult. It is rational to implement procedures to prevent these lesions. The present study was aimed to assess the effect of $\mathrm{CO}_{2}$ laser and fluoride varnish on the surface of the enamel surface microhardness around the orthodontic braces.

Methods: Eighty extracted premolar teeth were selected, scaled, polished with nonfluoridated pumic and metal brackets were bonded to them. Then, they were randomly allocated to 5 groups: control (neither fluoride nor laser is used on enamel surfaces), fluoride (4 minutes fluoride varnish treatment of the enamel surfaces), $\mathrm{CO}_{2}$ laser (10.6 $\mu \mathrm{m} \mathrm{CO}_{2}$ laser irradiation of the teeth), laserfluoride (fluoride application after laser irradiation) and fluoride-laser (fluoride was applied and then teeth were irradiated with laser). After surface treatment around brackets on enamel, the samples were stored in $0.1 \%$ thymol for less than 5 days and then they were exposed to a 10-day microbiological caries model. Microhardness values of enamel were evaluated with Vickers test. One sample of each group (5 teeth from 80 samples) was prepared for SEM (scanning electron microscopy) and the data from 75 remaining teeth were analyzed with analysis of variance (ANOVA) and chi-square tests $(\alpha=0.05)$.

Results: Microhardness mean values from high to low were as follow: fluoride-laser, laser-fluoride, laser, fluoride and control. Microhardness in fluoride-laser group was significantly higher compared with that of the control group. Distribution adhesive remnant index (ARI) scores were significantly different between groups and most of bond failures occurred the enamel-adhesive interface in groups 2 to 5 and at the adhesive-bracket interface in the control group.

Conclusion: Combination of fluoride varnish and $\mathrm{CO}_{2}$ laser irradiation can reduce enamel demineralization around orthodontic brackets.

Keywords: $\mathrm{CO}_{2}$ laser; Fluoride varnish; Demineralization; Orthodontic bracket.
\end{abstract}

\section{Introduction}

Orthodontic treatment has many advantages such as esthetic improvement, function and self-estimation enhancement. ${ }^{1}$ Orthodontic appliances make oral hygiene more difficult and increase plaque accumulation. After installing fix orthodontic appliances in the mouth, Streptococcus mutans and Lactobacillus species increase. These bacteria release organic acid that causes dissolution of ions of calcium and phosphate from the enamel surface, which can lead to white spot lesions and this process can occur in 4 weeks. ${ }^{2}$ White spot lesions are defined as enamel decalcification due to subsurface mineral loss; while 10 to $30 \mu \mathrm{m}$ of enamel surface remains intact. ${ }^{3,4}$ The opaque appearance of the lesion is due to variations in light scattering of decalcified porous enamel. Years after orthodontic treatment, white spot lesions may develop into esthetic problems, because demineralized enamel may absorb colors from drinks and foods. ${ }^{5,6}$ When the lesion progresses, remineralization gets tough and sometimes impossible ${ }^{5,7}$; hence, it is important to prevent the formation of these lesions. Øgaard reported that 5 years after treatment, white spot lesions were more 
prevalent in orthodontic patients compared with nontreated patients. ${ }^{8}$ It is obvious that this responsibility falls on the orthodontist to make patients aware of the demineralization risks. ${ }^{5}$ Modern dentistry concentrates more on prevention of lesions than their operation. ${ }^{9}$ Orthodontists should assess patients' risk factors throughout the treatment to prevent white spot lesions. Presence of the following factors increases the probability of white spot lesions occurrence: inappropriate oral hygiene, caries history or high decay missing filled surfaces (DMFS), and lack of preventive methods, such as fluoride or antibacterial compositions. ${ }^{10}$ Fluoride plays an important role in preventing demineralization during orthodontic treatment. Fluoride effects with different mechanisms: It joins the crystalline structure of hydroxy apatite and creates fluoride hydroxy apatite that is less soluble and more resistant to acidic attack, it increases the remineralization process and has antibacterial effects. ${ }^{11-13}$ There are different types of fluoride with different $\mathrm{pH}$, concentration and releasing systems such as varnish, gel, mouth-rinse and tooth paste. Complete compliance of patients with fluoride regimen at home is unlikely. Fluoride varnish is easy to use and does not depend on patient's cooperation. ${ }^{11,14}$

For patients with moderate to high risk of caries, fluoride regimen should be used at office every six months. ${ }^{10}$ Since the intervention of ruby crystal laser by Maiman in 1960, different lasers have been assessed in dentistry fields. ${ }^{15}$ Different types of lasers such as Er: YAG, Nd: YAG and $\mathrm{CO}_{2}$ with various adjusting parameters have been administrated for caries prevention. $\mathrm{CO}_{2}$ lasers are useful without hazardous side effects and they keep surface temperature at safe levels. $\mathrm{CO}_{2}$ lasers (with 9.3, 9.9, 10.3 and $10.6 \mu \mathrm{m}$ wavelengths) should be considered as main laser in caries prevention because the absorption bands of dentin, enamel, hydroxyle, carbonate and phosphates groups are in the range of 9-11 $\mu$ m. Irradiation of $\mathrm{CO}_{2}$ laser with $10.6 \mu \mathrm{m}$ wavelength and continuous beam causes significant decrease in the dissolving rate of enamel. After laser absorption, surface and near surface layer temperature increases which in turn causes structural and chemical changes in enamel. These changes include decomposition of organic matrix, decrease in carbonate compounds and fusion and recrystallization of hydroxyapatite crystals that causes a more resistant enamel to acid solution. ${ }^{16-22}$ It has been demonstrated that the effects of laser irradiation and topical fluoride may be synergistic. $^{23}$

\section{Methods}

A total of 100 human extracted premolar teeth with no caries, defects or hypoplastic enamel, were gathered and stored in saline. Scaling was done in order to removing calculus or tissue remnant. The buccal surface of the teeth was covered with acid-resistant varnish; however, a $4 \times 6$ $\mathrm{mm}$ window was left unexposed for bracket bonding and microhardness test. Twenty samples were used for pilot study which evaluated microbiological model efficacy for demineralization. Also, 5 samples were prepared for SEM and the data of the 75 remaining teeth were analyzed.

\section{Bonding of Brackets}

Enamel was etched by $37 \%$ phosphoric acid (3 M Unitek, Monrovia, USA), rinsed with water and dried with oilfree air for 15, 30 and 20 seconds, respectively, in order to obtain the appearance of a frosty white surface. Stainlesssteel brackets (Dentaurum, Ispringen, Germany) were bonded to premolars with the Transbond XT composite resin (3M Unitek, Monrovia, USA). Manufacturer's instructions were followed precisely in every stage. Brackets was placed in the correct position. The composite resin was cured for 40 seconds with an LED light-curing unit (Kerr, DEMI plus, USA). ${ }^{22}$

Then, the samples were randomly assigned to the following 5 experimental groups (16 teeth in each group): Group 1 (control): Neither fluoride nor $\mathrm{CO}_{2}$ laser was applied on the enamel surface at the gingival edge of brackets.

Group 2 (fluoride varnish): A thin layer of Fluoride varnish (5\% sodium fluoride varnish, Pascal, USA) was applied on the enamel surface using an applicator at the gingival edge of brackets. The varnish was left for 4 minutes and after 6 hours, teeth were cleaned with a toothbrush and distilled water.

Group 3 ( $\mathrm{CO}_{2}$ laser): $\mathrm{CO}_{2}$ laser (DEKA Laser Technologies, Florence, Italy) was irradiated to the enamel surface with the $5 \mathrm{~Hz}$ frequency, $10.6 \mu \mathrm{m}$ wavelength, $0.4 \mathrm{~W}$ output power, 0.9 seconds pulse time and $0.2 \mathrm{~mm}$ spot size by an experienced operator with a uniform scanning motion with $5 \mathrm{~mm}$ distance away from the enamel surface for 20 seconds totally. After irradiation, the samples were washed with distilled water.

Group 4 (laser before fluoride varnish): At first, the enamel surface at the gingival edge of bracket was irradiated with $\mathrm{CO}_{2}$ laser as explained for third group. Afterwards, fluoride varnish was applied according to the explained protocol of second group.

Group 5 (laser through fluoride varnish): Fluoride varnish was applied on the enamel surface at the gingival edge of brackets and laser irradiation was done 3 minutes later with the aforementioned parameters defined for third group through the varnish for 20 seconds. Afterwards, the teeth were rinsed with distilled water.

Finally, all samples were soaked in artificial saliva for a month. ${ }^{18}$

One sample from each group ( 5 teeth from 80 samples) was prepared for scanning electron microscopy (SEM) to observe the enamel surface (Figure 1).

\section{Demineralization Process}

At first, in order to prevent non-experimental bacteria contamination, 10 teeth were soaked in $0.1 \%$ thymol 


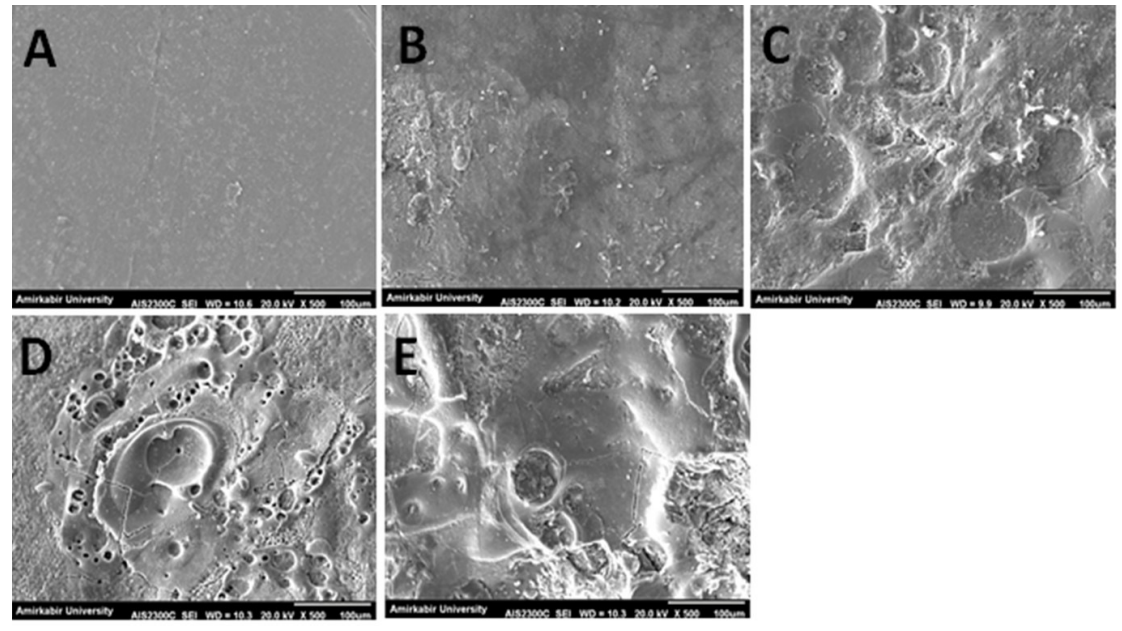

Figure 1. Enamel Surface of the Groups Observed in SEM Photomicrographs. A: group 1 (control) shows shallow depressions and small porosities without any surface deposits. B: group 2 (fluoride varnish) demonstrates numerous granular particles of fluoride on the enamel. C: group 3 (CO2 laser) with typical melting appearance, cracks and craters with discontinuities. D: group 4 (laser before fluoride varnish) shows a view similar to those of third group along with granular and globular particles. E: group 5 (laser trough fluoride varnish) demonstrates a relatively smoother and more homogeneous surface than those of the third group, with cracks and granular particles.

solution ${ }^{24}$; afterwards, caries model was used in order to simulate demineralization challenge. ${ }^{25}$

Streptococcus mutans (Clarke, ATCC ${ }^{\circledR}$ 35668TM Manassas, Virginia, USA) was chosen to grow biofilms on teeth and demineralize enamel. Culture medium was prepared by adding isolated $S$. mutans in $5 \mathrm{~mL}$ of tryptic soy agar (TSB) with $0.5 \mathrm{McF}$ arland turbidity to $80 \mathrm{~mL}$ of sterile brain-heart solution containing $5 \%$ sucrose. The samples were rinsed two times in a sterile plate with $0.9 \%$ saline near a flame and then placed in culture tubes in a jar with $10 \%$ partial $\mathrm{CO}_{2}$ at $37^{\circ} \mathrm{C}$. Every 24 hours, washing was repeated twice to remove loosely bound material from the enamel structure. Then, they were returned to the new culture medium. The continuation of the process was 10 days. ${ }^{25}$

Surface microhardness of the aforementioned teeth were compared to 10 non-exposed control teeth by surface microhardness test. The root of the teeth was cut $1 \mathrm{~mm}$ below CEJ and the crowns were placed in self-cured acrylic resin (Figure 2). Vickers microhardness testing machine (Micromet 1, Buehler LTD, Lake Bbluff, Illinois, USA) using a 300-g load with a dwell time of 15 seconds assessed the microhardness. Three indentations were

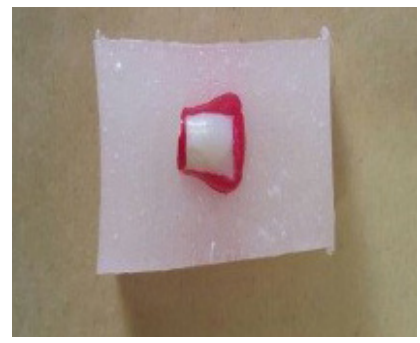

Figure 2. The Prepared Sample for Microhardness Test made on each sample in order to calculate the mean hardness as Vickers hardness number (VHN).

There was a statistically significant difference between exposed and non-exposed teeth $(P<0.05$, mean difference $=85$ ), and this pilot study showed that, as mentioned, microbiological model is effective in demineralizing the teeth.

Then 75 samples in 5 groups were demineralized through this method for 10 days.

Surface Microhardness Test

After the demineralization process, brackets were debonded and adhesive remnant index (ARI) was rated by an individual investigator according to the following protocol:

$1=$ the adhesive was remained on the enamel surface completely.

$2=$ more than half of the adhesive remnant observed on the surface of enamel.

$3=$ more than half of the adhesive remnant observed on the base of bracket.

$4=$ the adhesive remained on the bracket base completely. ${ }^{19}$ Then, the roots of the samples were cut $1 \mathrm{~mm}$ below the $\mathrm{CEJ}$ and the crowns were washed with distilled water and were mounted in self-cured acrylic resin in a way that the buccal surface was parallel to the horizon. A Vickers microhardness tester was used as explained previously and VHN was recorded. The indenter was positioned on a $2 \times 4-\mathrm{mm}$ non-bonded exposed surface of enamel.

\section{Results}

Surface Microhardness

Kolmogorov-Smirnov test revealed normal distribution of surface microhardness of the teeth in the 5 study 
groups. Means and 95\% CIs microhardness within the study groups are shown in Figure 3.

Microhardness mean values from high to low were as follow: fluoride-laser, laser-fluoride, laser, fluoride and control (Table 1).

The results of analysis of variance (ANOVA) revealed that there was a statistically significant difference among the 5 study groups $(P=0.03)$. Tukey post hoc test indicated that microhardness was statistically significantly higher in the fluoride-laser group compared with that of the control. (Table 2)

\section{Adhesive Remnant Index}

The results of ARI scores for ranking adhesive remnants on the enamel surfaces are shown in Table 3. According to chi-square analysis $\left(\chi^{2}=21.8, P=0.03\right)$, there were significant differences among the 5 groups in case of ARI scores. ARI scores of 3 and 4 were more prevalent in all experimental groups except for the control in which ARI score of 1 was higher. This indicated that bonding failure distributions were more at the adhesive-enamel interface in group 2 to 5 and at the bracket-adhesive interface in group 1.

\section{Discussion}

Orthodontic appliances make plaque removal and oral hygiene more difficult and so, increase the risk of white

Table 1. Mean and Standard Deviations of Microhardness in 5 Groups

\begin{tabular}{lcc}
\hline Groups & Mean $(\mathrm{KgN} / \mathbf{m m} \mathbf{2})$ & SD \\
\hline Control & 317.86 & 135.13 \\
Fluoride & 432.20 & 113.85 \\
Laser & 447.46 & 146.29 \\
Laser-fluoride & 460.64 & 150.64 \\
Fluoride-laser & 484.06 & 185.78 \\
\hline
\end{tabular}

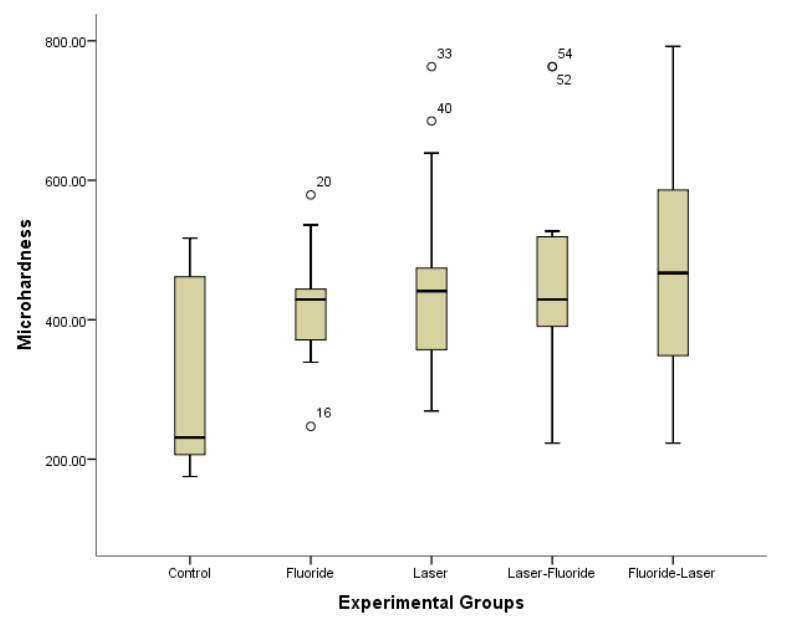

Figure 3. Differences in Vickers Hardness Values Between the Groups.

spot lesions. Clinically visible white spot lesions are observed in $50 \%$ of patients who received orthodontic treatment. ${ }^{21}$ In the present in vitro study, the effect of fluoride and $\mathrm{CO}_{2}$ laser irradiation on microhardness of enamel around orthodontic brackets were assessed. The mean values of microhardness from high to low were: fluoride-laser, laser-fluoride, laser, fluoride and control. Various methods have been used for assessing human tooth hardness, such as abrasion, scratch and indentation techniques. ${ }^{24}$ In the present study, Vickers microhardness test was utilized to assess changes in enamel surface as an indirect test that is capable of measuring the variations in surface structural strength from demineralization. ${ }^{26}$ In in vitro studies different methods are used for demineralization such as acidic solutions (citric acid, lactic acid), cariogenic solutions (Tencate) and microbiological models. ${ }^{12,21,25-27}$ In this study, a microbiological caries model with $S$. mutans was used. Microbiological caries models appear to be more appropriate than chemical

Table 2. Pairwise Comparisons Between Groups by Post Hoc Tukey Test for Vickers Hardness

\begin{tabular}{|c|c|c|c|c|c|c|}
\hline \multirow{2}{*}{ Group 1} & \multirow{2}{*}{ Group 2} & \multirow{2}{*}{ Mean Difference (1-2) } & \multirow{2}{*}{ SE } & \multirow{2}{*}{$P$ Value } & \multicolumn{2}{|c|}{$95 \% \mathrm{Cl}$} \\
\hline & & & & & Upper Bound & Lower Bound \\
\hline \multirow{4}{*}{ Control } & Fluoride & -114.33 & 54.12 & 0.22 & -265.87 & -37.21 \\
\hline & Laser & -129.60 & 54.12 & 0.12 & -281.14 & -21.94 \\
\hline & Laser-fluoride & -142.80 & 54.12 & 0.07 & -294.34 & -8.74 \\
\hline & Fluoride-laser & $-166.20^{a}$ & 54.12 & 0.02 & -317.74 & 14.65 \\
\hline \multirow{3}{*}{ Fluoride } & Laser & -15.26 & 54.12 & 0.99 & -166.81 & 136.27 \\
\hline & Laser-fluoride & -28.46 & 54.12 & 0.98 & -180.01 & 123.07 \\
\hline & Fluoride-laser & -51.86 & 54.12 & 0.87 & -203.41 & 99.67 \\
\hline \multirow{2}{*}{ Laser } & Laser-fluoride & -13.20 & 54.12 & 0.99 & -164.74 & 138.34 \\
\hline & Fluoride-laser & -36.60 & 54.12 & 0.96 & -188.14 & 114.94 \\
\hline Laser-fluoride & Fluoride-laser & -23.40 & 54.12 & 0.99 & -179.94 & 128.14 \\
\hline
\end{tabular}

Abbreviation: SE, standard error.

a The mean difference is significant at the 0.05 level. 
Table 3. ARI Scores Frequency and Results of Chi-Square Comparison of the 5 Groups

\begin{tabular}{lcccc}
\hline \multirow{2}{*}{ ARI Scores } & $\mathbf{1}$ & $\mathbf{2}$ & $\mathbf{3}$ & $\mathbf{4}$ \\
\cline { 2 - 5 } & No. $(\%)$ & No. $\mathbf{( \% )}$ & No. $\mathbf{( \% )}$ & No. $\mathbf{( \% )}$ \\
\hline Control & $5(33.3)$ & $2(13.3)$ & $4(26.7)$ & $4(26.7)$ \\
Fluoride & $0(0)$ & $2(13.3)$ & $7(46.7)$ & $6(40)$ \\
Laser & $1(6.7)$ & $1(6.7)$ & $6(40)$ & $7(46.7)$ \\
Laser-fluoride & $1(6.7)$ & $1(6.7)$ & $11(73.3)$ & $2(13.3)$ \\
Fluoride-laser & $0(0)$ & $3(20)$ & $5(33.3)$ & $7(46.7)$ \\
\hline
\end{tabular}

$d f=12, \chi^{2}=21.88, P$ value $=0.03$

models because they concentrate more on relevant biofilm aggregation instead of physiochemical aspects. ${ }^{21}$ We did a pilot study and it revealed that this microbial model can be effective in demineralizing the enamel.

There is consensus that fluoride decreased demineralization and increased demineralization via physical and chemical intervention, but its effect is partial and cannot prevent demineralization completely. So, the effect of their combination has been evaluated. They seem to have a synergistic effect on each other. ${ }^{28}$ According to the present study when fluoride is applied on the enamel and then laser irradiate through it, microhardness of enamel increases significantly compared with the control. It is reported that laser increased fluoride uptake. ${ }^{29,30}$ Stangler et $\mathrm{al}^{31}{ }^{31}$ Nakagaki et $\mathrm{al}^{32}$ and Featherstone et $\mathrm{al}^{33}$ assessed the effect of $\mathrm{CO}_{2}$ laser and fluoride combination and reported it to be more than fluoride or laser alone. With respect to the order of fluoride and laser in the combination, EstevesOliveira et $\mathrm{al}^{34}$ found that when fluoride is used before laser irradiation, it increased enamel microhardness more than when laser is used before fluoride application. In Steiner-Oliveira et al, ${ }^{25}$ Tagliaferro et $\mathrm{al}^{35}$ and Seino et $\mathrm{al}^{36}$ studies, the combination of fluoride and laser had not any additional effect compared with using them alone. Using different methods for demineralization and evaluation of enamel surface changes may cause these results to be different from those of the present study. In our study, microhardness of laser-fluoride group was higher than in the control, but it was not significantly different. Fluoride varnish remained at the tooth surface for hours after its consumption and released fluoride ions. Fluoride declined demineralization with its antibacterial effect while creating fluoride hydroxyl apatite which is more resistant to acidic attacks compared with hydroxyapatite. ${ }^{13}$ Effect of applying fluoride varnish alone has not been significantly different from control, which is similar to the study of Esteves-Oliveira ${ }^{34}$ in 2011. Melo et $\mathrm{al}^{37}$ evaluated the effect of different composites containing fluoride on prevention of demineralization around brackets using microbiological model and found that there was no significant difference between them. Todd et $\mathrm{al}^{38}$ reported that fluoride varnish caused $50 \%$ decrease in demineralization. They used polarized microscope for assessing enamel changes. Different types of lasers with various setting adjustments have been used for the purposes of preventing tooth caries. $\mathrm{CO}_{2}$ laser is effective and without hazardous side effects. ${ }^{30} \mathrm{CO}_{2}$ laser caused structural and supra-structural changes in enamel. ${ }^{28}$ In the present study, laser group had more microhardness values than the control but it was not significantly different. In the study of Steiner-Oliveira in 2010, using laser alone could not prevent enamel or dentin erosion. ${ }^{25}$ Miresmaeili et $\mathrm{al}^{22}$ reported that clinically, laser can increase enamel microhardness around brackets.

Present study showed a statistically significant difference between groups regarding the distribution of ARI scores and more bond failure distributions were at the enamelbracket interface in groups 2 to 5 and at the bracketadhesive interface in the control group. The results of Ladhe et $\mathrm{al}^{11}$ and Leódido et $\mathrm{al}^{39}$ studies about ARI were similar to ours.

While in the present study, microbiological model was used for demineralization to simulate clinical situation, saliva components and temperature conditions of the oral cavity can affect the effect of caries preventive materials. On the other hand, interaction of different species of aerobic and anaerobic bacteria in oral cavity with cariogenic species affects their operation and perhaps the pattern of demineralization. This study gives a point of view for using substrates clinically with the purposes of preventing enamel demineralization around brackets in orthodontic patients who are at the risk of caries.

\section{Conclusion}

Irradiating $\mathrm{CO}_{2}$ laser at wavelength of $10.6 \mu \mathrm{m}$ through fluoride varnish consumption on enamel around orthodontic brackets, increased enamel microhardness and so it can be used to prevent enamel demineralization in orthodontic patients.

In all of the treated groups, fracture of composite resins was occurred at composite-enamel interface. Further clinical trial studies are recommended to clarify these findings.

\section{Conflict of Interests}

The authors had no conflict of interest.

\section{Ethical Considerations}

There was no ethical consideration since the study was in vitro.

\section{References}

1. Buren JL, Staley RN, Wefel J, Qian F. Inhibition of enamel demineralization by an enamel sealant, Pro Seal: an in-vitro study. Am J Orthod Dentofacial Orthop. 2008;133(4):S88-S94. doi:10.1016/j.ajodo.2007.01.025.

2. Anderson AM, Kao E, Gladwin M, Benli O, Ngan P. The effects of argon laser irradiation on enamel decalcification: An in vivo study. Am J Orthod Dentofacial Orthop. 
2002;122(3):251-259.

3. Huang GJ, Roloff-Chiang B, Mills BE, et al. Effectiveness of MI Paste Plus and PreviDent fluoride varnish for treatment of white spot lesions: a randomized controlled trial. Am J Orthod Dentofacial Orthop. 2013;143(1):31-41. doi:10.1016/j.ajodo.2012.09.007.

4. Torlakovic L, Olsen I, Petzold C, Tiainen H, Ogaard B. Clinical color intensity of white spot lesions might be a better predictor of enamel demineralization depth than traditional clinical grading. Am J Orthod Dentofacial Orthop. 2012;142(2):191-198. doi:10.1016/j.ajodo.2012.03.025.

5. Øgaard B. White spot lesions during orthodontic treatment: mechanisms and fluoride preventive aspects. Semin Orthod. 2008;14(3):183-193. doi:10.1053/j.sodo.2008.03.003.

6. Bishara SE, Ostby AW. White spot lesions: formation, prevention, and treatment. Semin Orthod. 2008;14(3):174182. doi:10.1053/j.sodo.2008.03.002.

7. Willmot D. White Spot Lesions After Orthodontic Treatment. Semin Orthod. 2008;14(3):209-219. doi:10.1053/j.sodo.2008.03.006.

8. Øgaard B. Prevalence of white spot lesions in 19-near-olds: A study on untreated and orthodontically treated persons 5 years after treatment. Am J Orthod Dentofacial Orthop. 1989;96(5):423-7. doi:10.1016/0889-5406(89)90327-2.

9. Du M, Cheng N, Tai B, Jiang H, Li J, Bian Z. Randomized controlled trial on fluoride varnish application for treatment of white spot lesion after fixed orthodontic treatment. Clin Oral Investig. 2012;16(2):463-468. doi:10.1007/s00784011-0520-4.

10. Guzmán-Armstrong S, Chalmers J, Warren JJ. White spot lesions: Prevention and treatment. Am J Orthod Dentofacial Orthop. 2010;138(6):690-696. doi:10.1016/j. ajodo.2010.07.007

11. Ladhe KA, Sastri MR, Madaan JB, Vakil KK. Effect of remineralizing agents on bond strength of orthodontic brackets: an in vitro study. Prog Orthod. 2014;15(1):28. doi:10.1186/s40510-014-0028-y.

12. Sudjalim TR, Woods MG, Manton DJ, Reynolds EC. Prevention of demineralization around orthodontic brackets in vitro. Am J Orthod Dentofacial Orthop. 2007;131(6):705.e1-9. doi:10.1016/j.ajodo.2006.09.043.

13. Harald O, Edward J, Andre V. Sturdevant's Art and Science of Operative Dentistry. Elsevier; 2013.

14. Farhadian N, Miresmaeili A, Eslami B, Mehrabi S. Effect of fluoride varnish on enamel demineralization around brackets: an in-vivo study. Am J Orthod Dentofacial Orthop. 2008;133(4 suppl):S95-S98. doi:10.1016/j. ajodo.2006.09.050.

15. Steiner-Oliveira C, Rodrigues LK, Soares LE, Martin AA, Zezell DM, Nobre-dos-Santos M. Chemical, morphological and thermal effects of 10.6-microm CO2 laser on the inhibition of enamel demineralization. Dent Mater J. 2006;25(3):455-462.

16. Ahrari F, Poosti M, Motahari P. Enamel resistance to demineralization following Er:YAG laser etching for bonding orthodontic brackets. Dent Res J (Isfahan). 2012;9(4):472-477.

17. Bishara SE, Chan D, Abadir EA. The effect on the bonding strength of orthodontic brackets of fluoride application after etching. Am J Orthod Dentofacial Orthop. 1989;95(3):259-260.
18. Uysal T, Baysal A, Uysal B, Aydinbelge M, Al-Qunaian T. Do fluoride and casein phosphopeptide-amorphous calcium phosphate affect shear bond strength of orthodontic brackets bonded to a demineralized enamel surface? Angle Orthod. 2011;81(3):490-495. doi:10.2319/090510-520.1.

19. Tabrizi A, Cakirer B. A comparative evaluation of casein phosphopeptide-amorphous calcium phosphate and fluoride on the shear bond strength of orthodontic brackets. Eur J Orthod. 2011;33(3):282-287. doi:10.1093/ejo/cjq062.

20. Behnan SM, Arruda AO, Gonzalez-Cabezas C, Sohn W, Peters MC. In-vitro evaluation of various treatments to prevent demineralization next to orthodontic brackets. Am J Orthod Dentofacial Orthop. 2010;138(6):712.e1-7. doi:10.1016/j.ajodo.2010.05.014.

21. de Souza-e-Silva CM, Parisotto TM, Steiner-Oliveira C, Kamiya RU, Rodrigues LK, Nobre-dos-Santos M. Carbon dioxide laser and bonding materials reduce enamel demineralization around orthodontic brackets. Lasers Med Sci. 2013;28(1):111-118. doi:10.1007/s10103-012-1076-5.

22. Miresmaeili A, Farhadian N, Rezaei-soufi L, Saharkhizan M, Veisi M. Effect of carbon dioxide laser irradiation on enamel surface microhardness around orthodontic brackets. Am J Orthod Dentofacial Orthop. 2014;146(2):161165. doi:10.1016/j.ajodo.2014.04.023.

23. Rodrigues LK, Nobre dos Santos M, Pereira D, Assaf AV, Pardi V. Carbon dioxide laser in dental caries prevention. $J$ Dent. 2004;32(7):531-540. doi:10.1016/j.jdent.2004.04.004.

24. Gutiérrez-Salazar MP, Reyes-Gasga J. Microhardness and chemical composition of human tooth. Mater Res. 2003;6:367-373.

25. Steiner-Oliveira C, Nobre-dos-Santos M, Zero DT, Eckert $\mathrm{G}$, Hara AT. Effect of a pulsed CO2 laser and fluoride on the prevention of enamel and dentine erosion. Arch Oral Biol. 2010;55(2):127-133. doi:10.1016/j.archoralbio.2009.11.010.

26. Shahabi M, Ahrari F, Mohamadipour H, Moosavi H. Microleakage and shear bond strength of orthodontc brackets bonded to hypomineralized enamel following different surface preparations. J Clin Exp Dent. 2014;6(2): 110-115. doi:10.4317/jced.51254.

27. Reintsema $\mathrm{H}$, Arends J. An in vivo study of microhardness and fluoride uptake in partially demineralized human enamel covered by plaque. J Dent Res. 1988;67(2):471-473. doi:10.1177/00220345880670020701.

28. Poosti M, Ahrari F, Moosavi H, Najjaran H. The effect of fractional $\mathrm{CO} 2$ laser irradiation on remineralization of enamel white spot lesions. Lasers Med Sci. 2014;29(4):13491355. doi:10.1007/s10103-013-1290-9.

29. Tepper SA, Zehnder M, Pajarola GF, Schmidlin PR. Increased fluoride uptake and acid resistance by $\mathrm{CO} 2$ laserirradiation through topically applied fluoride on human enamel in vitro. J Dent. 2004;32(8):635-641. doi:10.1016/j. jdent.2004.06.010.

30. Chin-Ying SH, Xiaoli G, Jisheng P, Wefel JS. Effects of CO2 laser on fluoride uptake in enamel. J Dent. 2004;32(2):161167.

31. Stangler LP, Romano FL, Shirozaki MU, et al. Microhardness of enamel adjacent to orthodontic brackets after $\mathrm{CO} 2$ laser irradiation and fluoride application. Braz Dent J. 2013;24(5):508-512. doi:10.1590/0103-6440201302292.

32. Nakagaki S, Iijima M, Endo K, Saito T, Mizoguchi I. Effects of $\mathrm{CO} 2$ laser irradiation combined with fluoride application 
on the demineralization, mechanical properties, structure, and composition of enamel. Dent Mater J. 2015;34(3):287293. doi:10.4012/dmj.2014-225.

33. Featherstone JDB, Zhang SH, Shariati M, McCormack SM, editors. Carbon dioxide laser effects on caries-like lesions of dental enamel. Paper presented at: Optics, Electro-Optics, and Laser Applications in Science and Engineering; 1991.

34. Esteves-Oliveira M, Pasaporti C, Heussen N, Eduardo CP, Lampert F, Apel C. Rehardening of acid-softened enamel and prevention of enamel softening through $\mathrm{CO} 2$ laser irradiation. J Dent. 2011;39(6):414-421. doi:10.1016/j. jdent.2011.03.006.

35. Tagliaferro EP, Rodrigues LK, Nobre Dos Santos M, Soares LE, Martin AA. Combined effects of carbon dioxide laser and fluoride on demineralized primary enamel: an in vitro study. Caries Res. 2007;41(1):74-76. doi:10.1159/000096109.

36. Seino PY, Freitas PM, Marques MM, de Souza Almeida
FC, Botta SB, Moreira MS. Influence of CO2 (10.6 mum) and Nd:YAG laser irradiation on the prevention of enamel caries around orthodontic brackets. Lasers Med Sci. 2015;30(2):611-616. doi:10.1007/s10103-013-1380-8.

37. Melo MA, Morais WA, Passos VF, Lima JP, Rodrigues LK. Fluoride releasing and enamel demineralization around orthodontic brackets by fluoride-releasing composite containing nanoparticles. Clin Oral Investig. 2014;18(4):1343-1350. doi:10.1007/s00784-013-1073-5.

38. Todd MA, Staley RN, Kanellis MJ, Donly KJ, Wefel JS. Effect of a fluoride varnish on demineralization adjacent to orthodontic brackets. Am J Orthod Dentofacial Orthop. 1999;116(2):159-167.

39. Leódido GR, Fernandes HO, Tonetto MR, Presoto CD, Bandeca MC, Firoozmand LM. Effect of fluoride solutions on the shear bond strength of orthodontic brackets. Braz Dent J. 2012;23(6):698-702. 